\title{
Enantioselective trimethylsilylcyanation of benzaldehyde using pyrrolidine-based chiral salen ligands
}

\author{
M. Elisa Silva Serra,* Dina Murtinho, and Albertino Goth \\ Departamento de Química, Faculdade de Ciências e Tecnologia, Universidade de Coimbra, \\ P-3004-535 Coimbra, Portugal \\ E-mail: melisa@ci.uc.pt
}

Dedicated to Professor António M. d'A. Rocha Gonsalves, with recognition and esteem, on occasion of his $70^{\text {th }}$ birthday

\begin{abstract}
The in situ formed Ti(IV) complexes of several pyrrolidine-based chiral salen ligands derived from natural (L)-tartaric acid were evaluated as catalysts in the enantioselective trimethylsilylcyanation of benzaldehyde. The catalysts were found to be very active, producing the corresponding product, O-trimethylsilylmandelonitrile, in high yields (>94\%) and enantioselectivities of up to $88 \%$.
\end{abstract}

Keywords: Salens, tartaric acid, pyrrolidine, enantioselective, trimethylsilylcyanation, benzaldehyde

\section{Introduction}

The enantioselective trimethylsilylcyanation of aldehydes catalyzed by titanium complexes is a convenient process for the synthesis of optically active cyanohydrins. These chiral products have considerable synthetic interest, namely as precursors of molecules with other important functional groups, among which are $\alpha$-hydroxyacids, $\alpha$-hydroxyketones, primary and secondary $\beta$-hydroxyamines, $\alpha$-aminonitriles and $\alpha$-hydroxyesters. Titanium, vanadium and aluminium compounds have been successfully used as Lewis acids in these reactions and structurally diverse chiral ligands have proved efficient in this enantioselective process. ${ }^{1-6}$ Oguni's pioneering work with Schiff bases ${ }^{7-9}$ led to the development of many ligands of this type for the enantioselective trimethylsilylcyanation of aldehydes. ${ }^{10-16}$

Our research interests have focused on enantioselective catalysis studies, namely transfer hydrogenation of alkenes, ${ }^{17,18}$ alkylation of aldehydes with diethylzinc ${ }^{19-22}$ and, more recently, on the trimethylsilylcyanation of aldehydes with trimethylsilyl cyanide. ${ }^{23}$ We have devoted some 
attention to the synthesis of chiral salens from salicylaldehyde derivatives and chiral diamines with different backbone structures to be used as catalysts both in alkylations and trimethylsilylcyanations. This multiple application is possible due to the similarity in appropriate structural characteristics of these ligands for both types of enantioselective transformations. In this paper, we describe the results of the trimethylsilylcyanation of benzaldehyde using some pyrrolidine-based chiral salen ligands that we used previously in the enantioselective alkylation of aldehydes with diethylzinc. ${ }^{21}$

\section{Results and Discussion}

\section{Synthesis of chiral salen ligands}

The pyrrolidine-based chiral salen ligands $(3 R, 4 R)$-4a-f were prepared from natural (L)-tartaric acid, according to our previously described procedure ${ }^{21,23}$ as summarized in Scheme 1. Ligand 4c, which has not been previously described, was prepared similarly, by the condensation of (3R,4R)- $N$-benzyl-3,4-diaminopyrrolidine with 3-t-butylsalicylaldehyde, giving the corresponding salen, $(3 R, 4 R)-N^{\prime}, N^{\prime \prime}$-bis[3'-t-butylsalicylidene]- $N$-benzyl-3,4-diaminopyrrolidine in $71 \%$ yield.

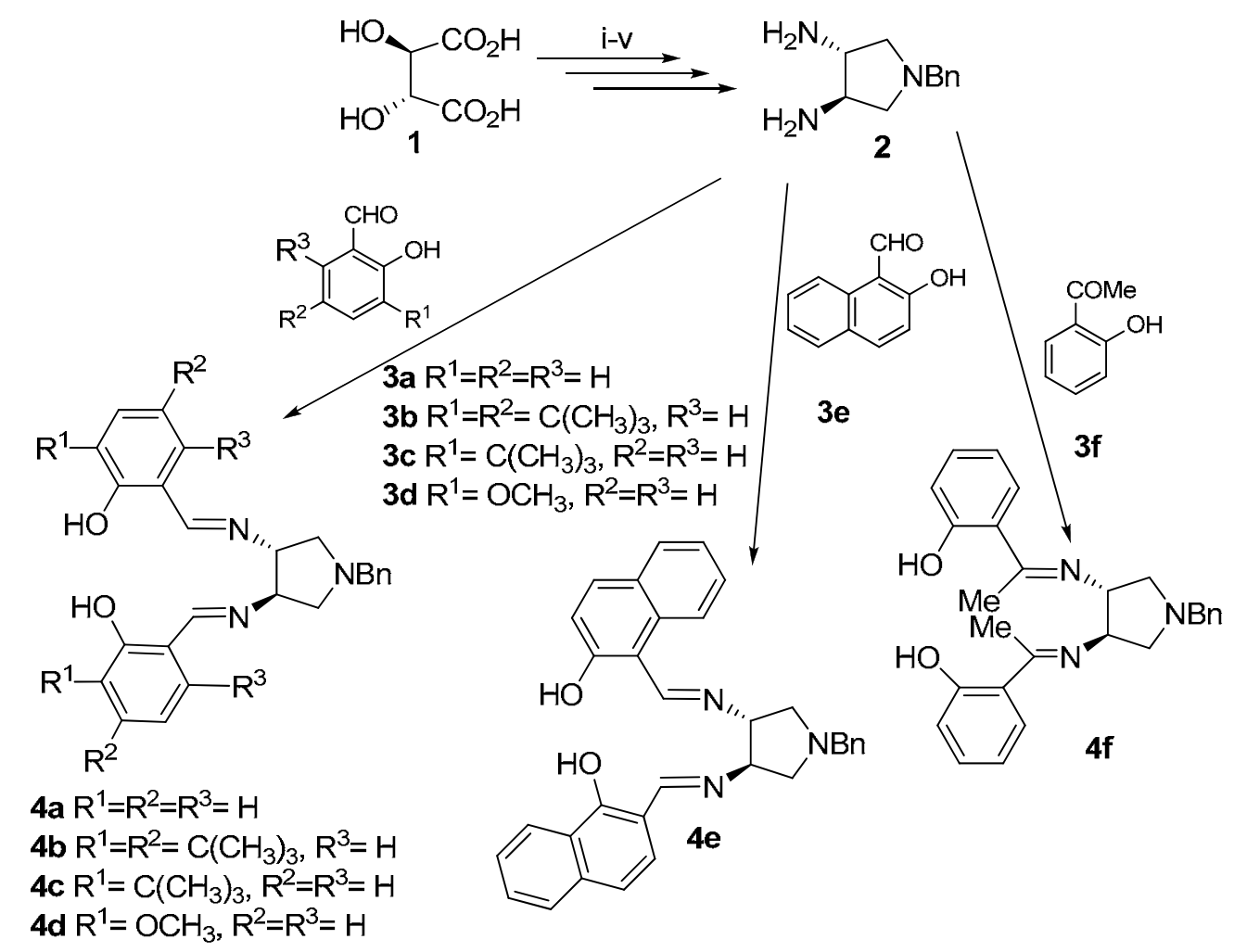

i.BnNH ${ }_{2}$, xylene, reflux. ï.AcCl, reflux. iii.. $\mathrm{LiAlH}_{4}$, ether, reflux. iv.DEAD/PPh $3, \mathrm{HN}_{3}$, rt. v. $\mathrm{H}_{2}, \mathrm{Pd} / \mathrm{C} 10 \%$.

\section{Scheme 1}




\section{Enantioselective trimethylsilylcyanation}

The titanium(IV) complexes of chiral salens $(3 R, 4 R)-\mathbf{4 a - f}$ were evaluated as catalysts in the enantioselective trimethylsilylcyanation of aldehydes, using benzaldehyde as model substrate, Scheme 2.

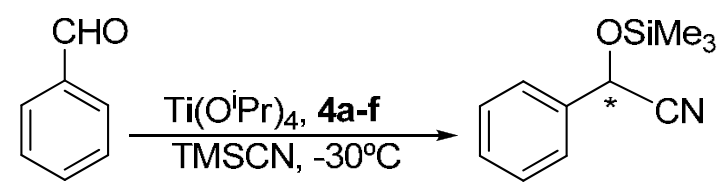

\section{Scheme 2}

All of the reactions were carried out in an inert $\mathrm{N}_{2}$ atmosphere for $24 \mathrm{~h}$ at $-30{ }^{\circ} \mathrm{C}$, using dichloromethane as solvent. The Ti:ligand:aldehyde:TMSCN ratio used was 1:1.1:5:10. The results of these catalytic experiments are summarized in Table 1.

Table 1. Enantioselective trimethylsilylcyanation of benzaldehyde ${ }^{a}$

\begin{tabular}{cccc}
\hline Entry & Salen & Conversion $^{\mathrm{b}}(\%)$ & $\mathrm{ee}^{\mathrm{c}}(\%)$ \\
\hline 1 & $(3 R, 4 R)-\mathbf{4 a}$ & 94 & $32(R)$ \\
2 & $(3 R, 4 R)-\mathbf{4 b}$ & $>99$ & $88(R)$ \\
3 & $(3 R, 4 R)-\mathbf{4} \boldsymbol{c}$ & 98 & $77(R)$ \\
4 & $(3 R, 4 R)-\mathbf{4}$ & $>99$ & $62(R)$ \\
5 & $(3 R, 4 R)-\mathbf{4} \boldsymbol{e}$ & 97 & $30(R)$ \\
6 & $(3 R, 4 R)-\mathbf{4} \boldsymbol{f}$ & 96 & $39(R)$ \\
\hline
\end{tabular}

${ }^{\mathrm{a}}$ Reaction was carried out on a $2 \mathrm{mmol}$ scale in $5 \mathrm{~mL}$ of dry $\mathrm{CH}_{2} \mathrm{Cl}_{2}$ at $-30{ }^{\circ} \mathrm{C}$, using a molar ratio of Ti:ligand:aldehyde:TMSCN of 1:1.1:5:10. ${ }^{\mathrm{b}}$ determined by gc. ${ }^{\mathrm{c}}$ of the silylether, determined by chiral gc.

Catalysts $\operatorname{Ti}[(3 R, 4 R)-\mathbf{4 a}-\mathbf{f}]$ were all found to be very active in promoting the trimethylsilylcyanation of benzaldehyde under our reaction conditions, giving conversions greater than $94 \%$. The ee of the products varied according to the structure of each particular ligand, the most selective being $(3 R, 4 R)-\mathbf{4 b}$, which originated the corresponding cyanosilylether with an ee of $88 \%$. A product with an ee of $77 \%$ was obtained when $(3 R, 4 R)-4 \mathrm{c}$ was used. The greater selectivities observed in the presence of these ligands is in agreement with our previous studies and with those of others which demonstrate that bulky groups in C3 and C3' and/or in C5 and $\mathrm{C5}^{\prime}$ of the aldehyde moieties of salen ligands are fundamental characteristics for high selectivity. ${ }^{7-12,23-25}$ The rigid cyclic backbone structure of the 1,2-diamine is probably also responsible for these selectivities. We have previously observed that, with the same aldehyde moieties but with less rigid backbone structures of 1,3-diamines derived from camphoric acid, lower selectivities are obtained. ${ }^{23}$ 
The major enantiomers of the cyanosilylethers obtained in these reactions presented $(R)$ absolute configuration, which results from an attack of the cyanide to the Si face of the aldehyde.

\section{Conclusions}

Chiral salens $(3 R, 4 R)$-4a-f were prepared according to previously established procedures and their Ti(IV)(salen) complexes used in the trimethylsilylcyanation of benzaldehyde. The studies described demonstrate that the catalysts are very active in trimethylsilylcyanations, where conversions greater than $94 \%$ were observed and selectivities of up to $88 \%$ were obtained, namely, in the presence of $(3 R, 4 R)-\mathbf{4 b}$ with two sterically demanding $t$-butyl substituents on each aldehyde moiety of the salen ligand.

\section{Experimental Section}

General Procedures. All solvents were dried prior to use following standard procedures. Titanium tetraisopropoxide was acquired from Aldrich and trimethylsilyl cyanide from Fluka. Benzaldehyde was distilled prior to use and stored over $4 \AA$ molecular sieves. All other reagents were used as commercially acquired. Melting points were determined using a Leitz-Wetzler 799 microscope, with a heated plate (values are uncorrected). Optical rotations were measured with an Optical Activity AA-5 polarimeter. NMR spectra were recorded on a Bruker Avance III 400 $\mathrm{MHz}$ spectrometer. TMS was used as the internal standard, chemical shifts are referred in $\delta$ and coupling constants, $J$, in Hz. Infrared spectra were recorded on a Thermo Scientific Nicolet 6700 FTIR (solids were processed as $\mathrm{KBr}$ pellets). Elemental analyses were carried out on a Fisons Instruments EA 1108 CHNS-O elemental analyser. GC analyses were recorded on a HP 5890A instrument coupled to an HP 3396A integrator using a capillary column (Supelcowax 10, $30 \mathrm{~m}, 0.25$ i.d., $0.25 \mu \mathrm{m})$. Mass spectra were recorded on a HP 5973 MSD chromatograph with $70 \mathrm{eV}$ (EI), Agilent 6890 series, equipped with an HP-5MS column (30m x $0.25 \mathrm{~mm} \times 0.25 \mu \mathrm{m})$ or on a Fisons Instruments-Platform with an APCI probe coupled to a Thermo Separation Spectra Series P200 chromatograph. Sonication was performed in a Bandelin Sonorex RK100H cleaning bath with a frequency of $35 \mathrm{~Hz}$ and a nominal power of 80/160 Watts.

Trimethylsilylcyanation reactions were carried out in an inert $\mathrm{N}_{2}$ atmosphere using standard Schlenk-type techniques. Reaction products were identified by gc/ms analysis and NMR spectroscopy. Catalytic experiments were repeated in order to confirm the reproducibility of results. Enantiomeric excesses were determined using a chiral $\gamma$-cyclodextrin capillary column (FS-Lipodex-E, 25 m, 0.25 i.d.) from Machery-Nagel, on an HP 5890A instrument coupled to an HP 3396A integrator. The absolute configuration of the major enantiomer was determined by comparison of the optical rotation with literature values. ${ }^{14,26}$ 


\section{Synthesis of $(3 R, 4 R)-N^{\prime}, N^{\prime \prime}$-bis[3'-t-butylsalicylidene]- $N$-benzyl-3,4-diaminopyrrolidine}

(4c). In a $25 \mathrm{~mL}$ Erlenmeyer flask, diamine (1R,3S)-1 (1.5 mmol, $0.139 \mathrm{~g})$ was dissolved in 5 $\mathrm{mL}$ of dry dichloromethane and the aldehyde $(3 \mathrm{mmol})$ and silica $(0.900 \mathrm{~g})$ were added. The mixture was placed in an ultrasound bath until the reaction was complete, as monitored by tlc, approximately $30 \mathrm{~min}$. The silica was filtered off, the solvent evaporated and the product was isolated by crystallization in ethanol/water, yielding $71 \%$ of the title compound. mp $65-67{ }^{\circ} \mathrm{C}$. $[\alpha]_{\mathrm{D}}{ }^{25}=-485\left(\mathrm{c} 1.0, \mathrm{CH}_{2} \mathrm{Cl}_{2}\right) .{ }^{1} \mathrm{H} \mathrm{NMR}\left(\mathrm{CDCl}_{3}\right): 1.44(\mathrm{~s}, 18 \mathrm{H}) ; 3.01$ (bs, 2H); 3.21 (bs, 2H); 3.81 (bs, 2H); 4.04 (bs, 2H); 6.78 (t, 2H, J 7.6), 7.05 (d, 2H, J 6.8); 7.25 (s, 2H); 7.29-7-37 (m, $3 \mathrm{H})$; 7.40-7.46 (m, 2H); $8.29(\mathrm{~s}, 2 \mathrm{H}) .{ }^{13} \mathrm{C} \mathrm{NMR}\left(\mathrm{CDCl}_{3}\right)$ : 29.35,34.83, 59.75, 60.06, 74.77, $118.07,118.31,127.56,128.51,129.06,129.85,130.06,137.37,160.23,166.48 . \mathrm{IR}\left(\mathrm{cm}^{-1}\right)$ : 2956, 2909, 1625, 1434, 1391, 1265, 1199, 1144, 1086, 796, 751, 699. Lc-ms: m/z 512 $\left[(\mathrm{M}+1)^{+}\right], 495,393,350,335,333,321$.

\section{General procedure for the trimethylsilylcyanation reactions}

To a solution of the chiral salen ligand $(0.44 \mathrm{mmol})$ in dry dichloromethane $(5 \mathrm{~mL}), \operatorname{Ti}\left(\mathrm{O}^{\mathrm{i}} \mathrm{Pr}\right)_{4}$ $(0.40 \mathrm{mmol}, 0.12 \mathrm{~mL})$ was added under an inert atmosphere at room temperature. The resulting mixture was stirred overnight and subsequently cooled to $-30{ }^{\circ} \mathrm{C}$. Benzaldehyde $(2 \mathrm{mmol}, 0.2$ $\mathrm{mL})$ and trimethylsilyl cyanide $(4 \mathrm{mmol}, 0.54 \mathrm{~mL})$ were added and the reaction stirred for $24 \mathrm{~h}$ at $-30{ }^{\circ} \mathrm{C}$.

At the end of the reaction, hexane was added and the precipitated solids were filtered off. Conversions were determined by gc and the ee of the resulting cyanosilyl ethers were determined by chiral gc analysis.

\section{Acknowledgements}

The authors would like to thank Chymiotechnon for financial support. We also thank the Nuclear Magnetic Resonance Laboratory of the Coimbra Chemistry Centre (www.nmrccc.uc.pt), University of Coimbra, supported in part by grant REEQ/481/QUI/2006 from FCT, POCI-2010 and FEDER, Portugal, for NMR spectra.

\section{References}

1. Brunel, J.-M.; Holmes, I. P. Angew. Chem., Int. Ed. 2004, 43, 2752.

2. Khan, N. H.; Kureshy, R. I.; Abdi, R.; Agrawal, S.; Jasra, R. V. Coord. Chem. Rev. 2008, 252, 593.

3. Gregory, R. J. H. Chem. Rev. 1999, 99, 3649.

4. Mori, A.; Inoue, S. In Comprehensive Asymmetric Catalysis; Jacobson, E. N.; Pfaltz, A.; Yamamoto, H.; Eds.; Springer: New York, 1999. Vol. II, Chapter 28. 
5. North, M.; Usanov, D. L.; Young, C. Chem. Rev. 2008, 108, 5146.

6. Gawronski, J.; Wascinska, N.; Gajewy, J. Chem. Rev. 2008, 108, 5227.

7. Hayashi, M.; Miyamoto, Y.; Inoue, T.; Oguni, N. J. Chem. Soc., Chem. Commun. 1991, 1752.

8. Hayashi, M.; Miyamoto, Y.; Inoue, T.; Oguni, N. J. Org. Chem. 1993, 58, 1515.

9. Hayashi, M.; Inoue, T.; Miyamoto, Y.; Oguni, N. Tetrahedron 1994, 50, 4385.

10. Flores-Lopéz, L. Z.; Parra-Hake, M.; Somanathan, R.; Walsh, P. J. Organometallics 2000, 19, 2153.

11. Gama, A.; Flores-Lopéz, L. Z.; Aguirre, G.; Parra-Hake, M.; Somanathan, R.; Walsh, P. J. Tetrahedron: Asymmetry 2002, 13, 149.

12. Gama, A.; Flores-Lopéz, L. Z.; Aguirre, G.; Parra-Hake, M.; Somanathan, R.; Cole, T. Tetrahedron: Asymmetry 2005, 16, 1167.

13. Belokon, Y. N.; Chusov, D.; Borkin, D. A.; Yashkina, L. V.; Dimitriev, A. V.; Katayev, D.; North, M. Tetrahedron: Asymmetry 2006, 17, 2328.

14. Rodrígues, B.; Pasto, M.; Jimeno, C.; Pericàs, M. A. Tetrahedron: Asymmetry 2006, 17, 151.

15. Belokon, Y. N.; Clegg, W.; Harrington, R. W.; Young, C.; North, M. Tetrahedron 2007, 63, 5287.

16. Zeng, Z.; Zhao, G.; Gao, P.; Tang, H.; Chen, B.; Zhou, Z.; Tang, C. Catalysis Comm. 2007, 8, 1443.

17. Rocha Gonsalves, A. M. d'A.; Bayón, J. C. ; Pereira, M. M.; Sliva Serra, M. E.; Pereira, J. P. R. J. Organomet. Chem. 1998, 553, 199.

18. Rocha Gonsalves, A. M. d'A.; Silva Serra, M. E.; Ramos Silva, M.; Matos Beja, A.; Paixão, J. A.; Alte da Veiga, L. J. Mol. Cat. A, Chem. 2001, 168, 53.

19. Rocha Gonsalves, A. M.; Silva Serra, M. E.; Murtinho, D.; Silva, V. F.; Matos Beja, A.; Paixão, J. A.; Ramos Silva, M.; Alte da Veiga, L. J. Mol. Cat. A: Chem. 2003, 195, 1.

20. Rocha Gonsalves, A. M.; Silva Serra, M. E.; Murtinho, D. J. Mol. Cat. A: Chem. 2006, 250, 104.

21. Silva Serra, M. E.; Murtinho, D.; Goth, A.; Rocha Gonsalves, A. M. d'A. Lett. Org. Chem. 2007, 4, 80 .

22. Silva Serra, M. E.; Murtinho, D.; Rocha Gonsalves, A. M. d’A. Appl. Organometal. Chem. 2008, 22, 488.

23. Silva Serra, M. E.; Murtinho, D.; Goth, A.; Rocha Gonsalves, A. M. d'A.; Abreu, P. E.; Canelas Pais, A. A. C. Chirality 2009, in press.

24. Jiang, Y.; Gong, L.; Feng, X.; Hu, W.; Pan, W.; Li, Z.; Mi, A. Tetrahedron 1997, 53, 14327.

25. Belokon, Y.; Moscalenko, M.; Ikonnikov, N.; Yashkina, L.; Antonov, D.; Vorontsov, E.; Rozenberg, V. Tetrahedron: Asymmetry 1997, 19, 3245.

26. Belokon, Y. N.; Yashkina, L. V.; Moscalenko, M. A.; Chesnokov, A. A.; Kublitsky, V. S.; Ikonnikov, N. S.; Orlova, S. A.; Tararov, V. I.; North, M. Russ. Chem. Bull. 1997, 46, 1936. 